\title{
Biopolítica e subjetividade: resistência?
}

\section{Biopolitics and subjectivity: resistance?}

\author{
Sílvio Gallo*
}

\begin{abstract}
RESUMO
O texto parte da hipótese de que está em curso no Brasil, nas últimas décadas, uma "governamentalidade democrática", isto é, a produção de ações de governo que consistem em constituir os sujeitos como cidadãos para que eles possam ser governados. Na maquinaria do biopoder, tal como pensada por Michel Foucault, o que acompanhamos são movimentos de construção de ações políticas que se exercem sobre as populações, como, por exemplo, as políticas públicas. Neste texto, percorremos transversalmente alguns documentos de políticas públicas brasileiras no campo da educação, desde a Lei de Diretrizes e Bases da Educação Nacional, de 1996, até a Base Nacional Comum Curricular, de 2017. O objetivo é o de mapear, nestas produções biopolíticas, os elementos que implicam na produção de um sujeito cidadão, como alvo das ações de governo. Ao final, são discutidas táticas de resistência a esta produção biopolítica, como recusa daquilo que somos, para a busca de novas produções subjetivas.
\end{abstract}

Palavras-chave: Biopolítica. Governamentalidade. Educação. Subjetividade.

\begin{abstract}
The paper starts from the hypothesis that a "democratic governmentality" has been taking place in Brazil for the last decades; that is, the production of government actions that consist in constituting subjects as citizens so that they can be governed. In the machinery of biopower, as conceived by Michel Foucault, what we are following are movements of construction of political actions that are exerted on the populations, as, for example, the public policies. In this text, we go over some Brazilian public policy documents in the field of education, from the Lei de Diretrizes e Bases da Educação Nacional ("the National Education's Law of Guidelines and Bases') from

DOI: $10.1590 / 0104-4060.53865$

* Universidade Estadual de Campinas. Faculdade de Educação. Campinas, São Paulo, Brasil. Rua Bertrand Russell, n 801. Cidade Universitária Zeferino Vaz. Cidade Universitária. CEP: 13083-865. E-mail: gallo@unicamp.br
\end{abstract}


1996 to the Base Nacional Comum Curricular ("the Curricular Common National Base") from 2017. The objective is to map, in these biopolitical productions, the elements that implicate in the production of a subject as a citizen, and a target of government actions. In the end, tactics of resistance to this biopolitical production are discussed, as a refusal of what we are, for the sake of the search for new subjective productions.

Keywords: Biopolitcs. Governmentality. Education. Subjectivity.

Como pensar a produção de subjetividade no contexto da biopolítica? Perseguiremos aqui os trabalhos do filósofo Michel Foucault em torno da biopolítica e da governamentalidade, focando-os a partir da questão do sujeito, de modo a procurar compreender a produção de políticas públicas em educação no Brasil contemporâneo e como tais políticas implicam na produção de um determinado tipo de sujeito, o cidadão como sujeito de direitos. Tais questões serão problematizadas conceitualmente, na tentativa de pensar possíveis resistências à produção subjetiva biopolítica contemporânea.

Para realizar esse objetivo, o artigo está organizado em três sessões. $\mathrm{Na}$ primeira, são realizadas explorações conceituais em torno das relações entre o sujeito e o poder na obra de Foucault, procurando situar a "virada subjetiva" que este autor produziu, mudando o foco de suas investigações. A segunda sessão apresenta a hipótese de que vivemos no Brasil nas últimas décadas a produção de uma biopolítica centrada na maquinaria de uma "governamentalidade democrática", orientada para produzir sujeitos cidadãos; tal ideia será pensada, de modo especial, no campo educativo, em torno das políticas públicas de educação fabricadas no passado recente. Por fim, uma terceira sessão procura pensar possíveis resistências no momento presente, investindo numa reafirmação da vida contra a vida totalmente governada por um Estado biopolítico.

\section{Sujeito e poder: explorações conceituais}

Em textos e entrevistas do início da década de 1980, Foucault afirmou ser o sujeito seu problema central, não o poder. Destaco, dentre vários exemplos possíveis desta afirmação, uma passagem emblemática para a temática aqui pensada: 
Eu gostaria de dizer primeiramente qual foi o objetivo de meu trabalho nesses últimos 20 anos. Não foi de analisar os fenômenos de poder nem de lançar as bases de tal análise. Procurei, antes, produzir uma história dos diferentes modos de subjetivação do ser humano em nossa cultura: tratei, nessa ótica, dos três modos de objetivação que transformam os seres humanos em sujeitos. [...]. Não é, pois, o poder, mas o sujeito que constitui o tema geral de minhas pesquisas. (FOUCAULT, 2014a, p. 118-119) ${ }^{1}$.

Os modos de objetivação apresentados por Foucault oferecem o panorama daquilo que ele pensou e produziu nas décadas anteriores: a ciência é apresentada como um modo de objetivação dos sujeitos, que permite que os seres humanos sejam pensados em sua ação (seres que vivem, trabalham, produzem); o segundo modo de objetivação é tomado das práticas divisoras, isto é, o conjunto de práticas que permitem classificar os seres humanos em distintas categorias como, por exemplo, o normal e o anormal, o louco e o "são de espírito", o doente e o sadio. Por fim, a terceira forma de objetivação pode ser percebida numa autoposição do sujeito, isto é, a maneira pela qual um ser humano se transforma em sujeito e age sobre si mesmo, como exemplo é citado seu estudo em torno da sexualidade. O que vemos, então, é uma análise retrospectiva do trabalho do filósofo, em que o sujeito é colocado como preocupação central. Seja nos estudos arqueológicos em torno da constituição dos saberes, seja nos estudos genealógicos em torno da formação e funcionamento das maquinarias de poder, o foco das investigações trata sempre do sujeito (sujeito de saber no primeiro caso, sujeito de poder no segundo caso). Importante destacar, o sujeito é pensado em duplo aspecto: como sujeito da ação (de conhecer, de exercer poder), mas também como objeto da ação (sujeito humano que é conhecido como objeto de um saber científico, sujeito submisso a um poder); o que significa que os processos de subjetivação (de constituição de sujeitos) são também processos de objetivação. O sujeito não pode ser pensado, tematizado, abordado, senão como resultante deste feixe de processos, às vezes, contraditórios entre si.

Outra observação de natureza conceitual muito importante. Quando Foucault fala de sujeito não está, evidentemente, referindo-se ao sujeito moderno, autocentrado e autorreferenciado. O sujeito pensado e estudado por Foucault é resultante de processos de objetivação, como afirmado, mas também age sobre

$1 \mathrm{O}$ trecho aqui citado é do texto intitulado $O$ sujeito e o poder, escrito originariamente em inglês e publicado em 1982 como um dos posfácios do livro de Dreyfus e Rabinow, Michel Foucault beyond structuralism and hermeneutics, retomado depois na edição dos Dits et Écrits na França. Outro texto referencial para esta questão é a entrevista Verdade, poder e si mesmo, publicada originariamente em 1988 e também retomado nos Dits et Écrits. 
si mesmo, transformando-se. Por esta razão, o filósofo insistiu em enfatizar a expressão "si mesmo". Não se trata do sujeito identitário que diz "eu”, mas de um nó de relações exteriores e interiores que possibilitem que tal sujeito pense a si mesmo no momento em que age. Em um seminário nos Estados Unidos em $1980^{2}$, Foucault teve a oportunidade de deixar clara sua concepção sobre a expressão "si mesmo":

Como vocês sabem, não temos [o equivalente da] palavra "self" em francês; é uma pena, porque penso ser uma boa palavra. Em francês, temos duas palavras, "sujeito" e "subjetividade", e não sei se vocês usam com frequência "subjetividade", penso que não. Vejam: por "si" eu entendo o tipo de relação que o ser humano enquanto sujeito pode ter e nutrir com ele mesmo. Por exemplo, o ser humano pode ser, na cidade, um sujeito político. Sujeito político, isso quer dizer que ele pode votar, ou que ele pode ser explorado pelos outros etc. O si seria o tipo de relação que este ser humano enquanto sujeito tem com ele mesmo numa relação política. Podemos chamar isso de "subjetividade" em francês, mas não é satisfatório, eu penso que "si" é melhor. E este tipo de relação do sujeito consigo mesmo é, eu creio, o alvo das técnicas... (FOUCAULT, 2013, p. 131).

O sujeito é, pois, aquele que age e que sofre ações de outrem; o si mesmo é a relação que este sujeito estabelece consigo mesmo enquanto agente. É este "nó de relações" que, segundo Foucault, opera como o alvo das técnicas de si, conjunto de operações de constituição subjetiva. As técnicas de si não operam nem sobre os jogos de poder, nem sobre as relações de saber, nem sobre as determinações sociais, mas agem diretamente sobre essa relação que o sujeito estabelece consigo mesmo enquanto vive e age. Gilles Deleuze (1991), em seu comentário da obra de Foucault, fala na subjetividade como "dobras" entre o "dentro" (o sujeito em relação consigo mesmo, em uma "interioridade") e o "fora" (o sujeito na relação com as múltiplas forças do exterior) ${ }^{3}$.

2 Nos dias 17 e 24 de novembro de 1980, Foucault proferiu duas conferências no Dartmouth College na cidade de Hanover, New Hampshire, intituladas Verdade e subjetividade e Cristianismo e confissão. As duas conferências foram publicadas em francês apenas em 2013, e o trecho citado foi retirado do debate seguido à primeira delas.

3 “Quais são as nossas quatro dobras?", pergunta-se Deleuze (1991, p. 112), e discorre sobre como elas aparecem e são tratadas ao longo da obra de Foucault. E um pouco adiante, ao tratar do pensamento, coloca: "Se o lado de dentro se constitui pela dobra do de fora, há sempre entre eles uma relação topológica: a relação consigo é homóloga à relação com o lado de fora, e os dois estão em contato, intermediado pelos estratos, que são meios relativamente exteriores (portanto relativamente 
Nesse contexto, a questão que se nos impõe pode ser apresentada da seguinte forma: Como pensar as relações entre sujeito e poder, de modo especial no âmbito da biopolítica? Como pensar a constituição dos sujeitos, a produção da subjetividade, na direção disso que o filósofo denominou o "si", que consiste na percepção do sujeito na atividade mesma (por exemplo, o perceber-se a si como sujeito político, o perceber-se a si como sujeito de saber etc.)?

Para enfrentar tal problemática, exploraremos em que linhas se dá essa "virada subjetiva" em Foucault, posto que a inflexão de seus estudos em direção ao sujeito dá-se no contexto dos trabalhos em torno da governamentalidade, uma vez que essa noção se produz exatamente na dobra entre o governo dos outros e o governo de si mesmo ${ }^{4}$. Muriel Combes (2011, p. 57) oferece uma chave analítica importante: "colocar a questão do sujeito a partir de seus modos de objetivação não pode ser feito senão pela ajuda de uma questão do poder como governo"; isto é, enquanto Foucault não chega à noção do exercício do poder como atos de governo, o sujeito não pode ser tematizado, senão como objeto das relações de poder. Ao ser posta a questão do governo como operador conceitual, por sua dupla inflexão (governar aos outros e governar a si mesmo) o sujeito passa a ser tematizado como agente, não apenas como objeto sujeitado. Por isso, dos estudos sobre governamentalidade, que, por sua vez, se desdobram das análises em torno da biopolítica, o sujeito pode emergir como operador conceitual na analítica de Foucault.

O percurso estudado por Combes é indicado pela autora como sendo uma transição de um "sujeito do biopoder" a um "sujeito ético". Após estudar um conjunto de textos de Foucault concernentes a esta temática, ela aponta:

O conjunto dos "pontos críticos" sublinhados pode sugerir o seguinte: ente 1980 e 1982, a tomada da questão do sujeito, tão próxima daquela da governamentalidade, é indissociável de uma oscilação na qual o governo de si por si mesmo parece compreender tanto a obediência a outro exemplo do poder pastoral, em que se trata, para o dirigido, de reconhecer

interiores)". (DELEUZE, 1991, p. 127). Isto evidencia que a "interioridade" do sujeito não aponta para um núcleo subjetivo identitário, para uma essência que faz com que o sujeito seja quem ele é; esta interioridade nada mais é do que uma dobra do exterior no "interior", de modo que o sujeito é constituído pelas relações que estabelece com as forças que o constituem. Em outras palavras, o sujeito se constitui a si mesmo com a matéria das sujeições (objetivações) que sofre.

4 Castro evidencia o duplo sentido da governamentalidade: de um lado, o modo de funcionamento dos Estados governamentalizados modernos, indicando assim "a análise das formas de racionalidade, de procedimentos técnicos, de formas de instrumentalização" (CASTRO, 2009, p. 191); de outro lado, o encontro das técnicas de dominação (isto é, os modos de exercício de poder) com as técnicas de si. 
que a verdade de si mesmo passa pela relação com o desejo e pela luta contra ele, obedecendo a seu diretor -, quanto a ótica da construção de si - assim, na direção de consciência estoica, que visa a mestria de si pelo dirigido, que pode vir a ser, por sua vez, "diretor" de seu diretor, na medida em que torna-se mestre de si mesmo. É verdadeiramente nessa linha de hesitação, linha em zigue-zague do governo de si que o acento é posto tanto na relação de obediência ao outro ou de comando do outro, quanto na relação de construção de si, que aparece com o projeto de uma história do cuidado [inquietude] de $\mathrm{si}^{5}$, e em torno de uma noção de experiência, uma linha ao longo da qual a questão do sujeito se separa visivelmente da análise do biopoder. Ao orientar o problema do sujeito pelo lado da governamentalidade, depois pelas técnicas de si, a análise finalmente se separa da problemática do biopoder. (COMBES, 2011, p. 60).

Segundo Combes, após desembaraçar-se da biopolítica, o sujeito passa a ser pensado por Foucault na direção da constituição de um "sujeito ético", o que o direciona para um novo campo conceitual. Porém, aqui precisamos insistir um pouco mais nessa "linha de hesitação" que ela aponta, para pensar os elementos da subjetivação no contexto da biopolítica. Para isso, busco outros elementos em Jean-Pierre Audureau, que publicou na Revue Française de Pédagogie, em 2003, um dos poucos artigos em língua francesa que visam pensar Foucault no campo da educação, intitulado "Assujeitamento e subjetivação: reflexões sobre o uso de Foucault em educação".

Por assujeitamento Audureau compreende a produção do sujeito pelas relações de poder, o sujeito tomado como efeito das relações de poder. $\mathrm{Na}$ obra de Foucault mobilizada para pensar o campo educativo, ele localiza esta analítica, sobretudo, em Vigiar e Punir (1991). Mas é importante destacar que o processo de assujeitamento não é a produção de sujeitos puramente submetidos; o assujeitamento é a objetivação, o sujeito tomado como alvo - e efeito - das relações de poder que fazem com que ele seja constituído enquanto sujeito. $\mathrm{O}$ autor esclarece:

O efeito de assujeitamento produzido pelas técnicas disciplinares não significa, aqui, captura, escravização. É uma espécie de ligação com a concepção jurídica do poder que nos faz pensar no modelo de um poder

5 Ainda que se tenha convencionado traduzir no Brasil por "cuidado de si" a expressão francesa souci de soi, proposta por Foucault para traduzir a noção grega de epimeleia heautou, parece-me que a expressão "inquietude de si" indica melhor o sentido que se depreende das expressões francesa e grega. 
tirânico como oprimindo ou reprimindo sujeitos já constituídos. Não há sujeito previamente dado, sobre o qual viria aplicar-se a disciplina, mas produção pela maquinaria disciplinar de seu próprio ponto de aplicação. O assujeitamento é, claro, produção do sujeito, de uma "sujeição", de uma docilidade, mas também, e sobretudo, é produção de uma subjetividade. E contra todos os nossos hábitos mentais, é através desta subjetividade que as disciplinas visam a sujeição. $\mathrm{O}$ sujeito seria, então, menos este princípio em torno do qual a escola moderna pretende se organizar do que um efeito - e se ela contribui com os mecanismos de dominação é menos porque insidiosamente ela manteria neste e naquele elemento de seu funcionamento traços de despotismo, do que a medida mesma em que ela produz tais sujeitos. Aquilo que serve para legitimar a escola no contexto das educações tradicionais poderia, pois, tornar-se o princípio de sua incriminação. (AUDUREAU, 2003, p. 20-21).

A escola como lugar de produção de sujeitos, pois, é o que encontramos nesta obra de Foucault. Se o sujeito é um efeito do poder disciplinar, ele não é menos efeito do biopoder. Uma vez individualizado pelas técnicas disciplinares, ele torna-se alvo dos sistemas de controle populacional e voltaremos a isso em seguida. Por ora, cumpre ainda trazer algumas palavras sobre o processo de subjetivação: trata-se da constituição do sujeito, do si mesmo como alvo de todas as técnicas, no seio das relações de poder. Claro que as duas instâncias não podem ser tomadas de forma estanque ou em separado; didaticamente as separei para melhor compreender, mas apenas em conjunto elas podem nos ajudar a compreender essa linha de hesitação, esse zigue-zague entre dois polos que são responsáveis pela constituição de cada um.

Ainda em relação a uma "virada subjetiva" em Foucault, ela pode ser notada claramente no curso de 1980, O governo dos vivos (2014c), destinado ao estudo das técnicas de subjetivação nos primeiros séculos do cristianismo, para compreender como elas impactam a nós na contemporaneidade. Após analisar os mecanismos do biopoder e da biopolítica nos anos anteriores, aqui vemos um deslocamento na analítica do poder, que o filósofo identifica como um deslocamento da análise do tipo poder-saber para uma análise do governo dos seres humanos pela verdade ${ }^{6}$.

O curso é finalizado com a demarcação dessa relação da subjetividade com a verdade, com três observações que podem ser resumidas como segue:

6 Consultar a primeira aula, de 9 de janeiro de 1980, em Foucault (2014c), de modo especial as páginas 12 e 13 . 
a) Na subjetivação cristã, matéria do estudo no curso, trata-se de orientar a veridição para uma renúncia a si, na contramão da perfeição buscada, por exemplo, pelos estoicos. É essa renúncia à perfeição que torna possível uma religião de salvação.

b) O cristianismo impõe uma necessidade de falar a verdade sobre si mesmo, através das mais diferentes técnicas (o batismo, a penitência, a exomolegese, a exagoreusis) ${ }^{7}$. Já não é Édipo rei que precisa descobrir a verdade de si; é qualquer um, somos todos nós, e temos que confessá-la, somos levados a dizê-la publicamente. É neste ato que se é constituído como sujeito ${ }^{8}$.

c) Essa relação entre subjetividade e verdade, entre o sujeito e a explicitação (pela fala) da verdade de si implica em um poder. O sujeito se constitui como tal quando fala e manifesta sua verdade, mas só o faz por constrangimento: é-se obrigado a confessar sua verdade para que se possa ser salvo.

Sobre esse constrangimento por um poder, afirmou Foucault:

Essa institucionalização das relações verdade/subjetividade pela obrigação de dizer a verdade sobre si, essa organização desse vínculo não pode ser concebida sem a existência e o funcionamento de uma forma de poder que, é claro, [cujo estudo] eu não quis empreender esse ano [...] O cristão tem a verdade no fundo de si mesmo e é atrelado a esse segredo profundo, ele está infindamente debruçado sobre si e infindamente obrigado a mostrar ao outro o tesouro que seu trabalho, seu pensamento, sua atenção, sua consciência, seu discurso não param de extrair deles. E é com isso que mostra que a discursivização da sua própria verdade não é simplesmente uma obrigação essencial. É uma das formas primeiras da nossa obediência. (FOUCAULT, 2014c, p. 283).

7 Sobre essas técnicas, consultar o curso já citado (FOUCAULT, 2014c) e também o texto As técnicas de si (FOUCAULT, 2014b).

8 Seria muito interessante desenvolver uma comparação entre essa abordagem de Foucault que indica que o sujeito se constitui nessa obrigação de dizer, de confessar sua verdade, com a análise feita por Althusser em princípios dos anos 1970, na qual afirma que "a ideologia interpela os indivíduos como sujeitos" (FOUCAULT, 1999, p. 283). Para o antigo professor de Foucault, o sujeito se constitui quando ouve uma interpelação externa - de um discurso ideológico, como o religioso, por exemplo - e se reconhece nele. O ex-aluno, que em diversos momentos, como no curso de 1980, afirmou buscar alternativas à análise de tipo ideológico, marca o processo de subjetivação por um dizer a verdade de si mesmo, não em reconhecer uma verdade que se ouve. 
Ora, o que vemos aqui é Foucault remeter a subjetivação cristã ao poder pastoral $^{9}$, a esse jogo de direção de consciência que implica no exercício de cada um falar de si, buscar a verdade em seu interior e confessá-la a seu diretor. Alguém se constitui sujeito à medida que fala sua verdade, mas falar sua verdade é um ato de obediência. É o poder que subjetiva, assujeitando. Institui-se, assim, um "governo de si pela verdade".

Não podemos esquecer que, ao analisar a biopolítica, Foucault afirmava que ela é uma reativação do poder pastoral; de modo que uma subjetivação biopolítica passa, necessariamente, por uma afirmação de si no ato de ser conduzido. Em outras palavras, o biopoder constitui sujeitos para governá-los. Sermos sujeitos é nossa maneira de sermos governados em termos biopolíticos.

Postas essas considerações sobre o sujeito e a subjetividade no contexto da biopolítica, buscaremos agora pensar a contemporaneidade brasileira em termos biopolíticos. Como compreender nossa realidade política nessa direção? Será possível estabelecer as bases do governo biopolítico no Brasil contemporâneo? Que efeitos um tal governo provoca em nossa constituição subjetiva?

\section{Biopolítica made in Brazil: em torno de uma "governamentalidade democrática”}

A análise que Foucault desenvolveu nos cursos de 1978 (Segurança, território e população) e 1979 (Nascimento da biopolítica) diz respeito aos Estados europeus modernos. Ele mostrou como houve uma progressiva transição de um Estado de justiça, baseado na maquinaria da soberania, para um Estado administrativo, centrado na tecnologia disciplinar; e, finalmente, para um Estado de governo, articulado em torno do biopoder, o que o levou a afirmar que o processo de governamentalização do Estado foi mais importante do que o processo de estatização da sociedade (FOUCAULT, 2008b, p. 144-145). Tal Estado governamentalizado está amparado na perspectiva de que se governam pessoas mais do que territórios, e este Estado assenta-se, em última medida, na prática do poder pastoral que, embora praticado no ocidente, tem suas origens em práticas orientais mais do que no modelo grego. O modelo de governo grego estava centrado na metáfora do piloto que dirige o barco: governa-se o navio assim como se governa a cidade; as pessoas são governadas enquanto estão

9 O poder pastoral já havia sido analisado em profundidade no curso de 1978 (FOUCAULT, 2008b), em especial nas aulas de 08, 15, 22 de fevereiro e 01 de março. 
presentes no navio ou na cidade (FOUCAULT, 2008a, p. 165-166). O modelo pastoral, por outro lado, está centrado no pastor que governa seu rebanho: governam-se pessoas, não um território. Embora provenha de uma prática oriental, o pastor que cuida de seu rebanho, o poder pastoral encontrará um meio de cultura propício na medievalidade europeia, consolidando-se juntamente com as práticas cristãs. Importante notar com esta metáfora: governar um rebanho não é apenas dirigi-lo, mas também cuidar dele; cuidar do rebanho como um todo, mas também de cada indivíduo que o compõe.

A prática de governar pessoas encontra-se com a consolidação da biopolítica, esta é orientada para um controle populacional e para o governo deste novo corpo político. Assim Foucault caracteriza sua emergência:

As disciplinas lidavam praticamente com o indivíduo e com seu corpo. Não é exatamente com a sociedade que se lida nessa nova tecnologia de poder [...] É um novo corpo: corpo múltiplo, corpo com inúmeras cabeças, se não infinito pelo menos necessariamente numerável. É a noção de "população". A biopolítica lida com a população, e a população como problema político, como problema a um só tempo científico e político, como problema biológico e como problema de poder [...]. (FOUCAULT, 1999, p. 292-293).

Dirigindo-se a uma população, o Estado biopolítico governa pessoas, não como súditos submetidos a um poder central, mas indivíduos que participam de modo ativo da produção da vida coletiva. O Estado governamentalizado biopolítico europeu consolida-se, pois, como o Estado democrático moderno, resultado de um processo de construção histórica que envolve diferentes tecnologias de poder. Ora, sabe-se que no Brasil, fruto da colonização, a constituição do Estado seguiu fluxos distintos, de modo que não podemos falar em um Estado governamentalizado antes do século XX. De modo especial, temos um marco na década de 1980, com o fim da ditadura civil-militar que durou duas décadas: assistimos então a um grande esforço de constituição de um Estado democrático, centrado na afirmação dos direitos humanos e civis dos cidadãos, na construção de seus marcos legais, mas também, e sobretudo, na construção de uma forma de governar nitidamente inscrita na biopolítica, no governo das populações, mais do que territórios.

Nesse contexto, tenho defendido a hipótese de que podemos analisar a constituição política brasileira das últimas três décadas em torno da perspectiva de uma "governamentalidade democrática", centrada na afirmação da cidadania, uma vez que é preciso ser cidadão para que se possa ser governado democrati- 
camente e não de forma autoritária. Após 21 anos de regime de exceção e com a redemocratização do país, em fevereiro de 1987, foi instalada uma Assembleia Nacional Constituinte que encerraria seus trabalhos em setembro do ano seguinte, com a aprovação da Constituição da República Federativa do Brasil de 1988. No seu preâmbulo, lemos:

\begin{abstract}
Nós, representantes do povo brasileiro, reunidos em Assembleia Nacional Constituinte para instituir um Estado Democrático, destinado a assegurar o exercício dos direitos sociais e individuais, a liberdade, a segurança, o bem-estar, o desenvolvimento, a igualdade e a justiça como valores supremos de uma sociedade fraterna, pluralista e sem preconceitos, fundada na harmonia social e comprometida, na ordem interna e internacional, com a solução pacífica das controvérsias, promulgamos, sob a proteção de Deus, a seguinte CONSTITUIÇÃO DA REPÚBLICA FEDERATIVA DO BRASIL. (BRASIL, 1988).
\end{abstract}

Note-se o acento de que esta legislação foi firmada por "representantes do povo brasileiro", visando o "exercício dos direitos sociais e individuais". Trata-se de instituir um regime democrático de governo, no qual ser governado é participar dos atos de governo. O texto constitucional elegeu cinco princípios fundamentais, apresentados após este preâmbulo, sendo o segundo deles a cidadania, indicada logo após a soberania. Faço este destaque para deixar clara a intencionalidade de constituição de um Estado democrático de direito, amparada na afirmação e na promoção da cidadania como um dos princípios fundamentais. A Constituição indica um claro desejo de fundamentar um processo de governo democrático no país e estabelece as bases para sua consolidação. Como no registro da biopolítica, o que se governa são populações, tivemos após a promulgação deste marco legal maior uma intensa produção de políticas públicas nos mais variados campos, como forma de constituir tal processo de governamento populacional, no qual todos os cidadãos devem estar devidamente incluídos.

No campo da educação, um dos alvos do governo biopolítico das populações, tivemos amplos debates sociais e políticos que culminaram com a aprovação da Lei de Diretrizes e Bases da Educação Nacional em 1996, no marco legal da nova Constituição federativa. Também aqui a palavra-chave da cidadania brilha como pedra de toque dos esforços governamentais. Em seu artigo segundo, lemos: "A educação, dever da família e do Estado, inspirada nos princípios de liberdade e nos ideais de solidariedade humana, tem por finalidade o pleno desenvolvimento do educando, seu preparo para o exercício da cidadania e sua qualificação para o trabalho" (BRASIL, 1996, grifo meu). 
Seria possível traçarmos uma linha transversal que parte da Lei de Diretrizes e Bases da Educação Nacional (BRASIL, 1996) até a Base Nacional Curricular Comum - BNCC (BRASIL, 2017) para o Ensino Fundamental, atravessando os Parâmetros Curriculares Nacionais, as Orientações Curriculares Nacionais, as Diretrizes Curriculares para Cursos de Graduação, as políticas específicas para educação infantil, para os ensino fundamental e médio, as políticas afirmativas da diversidade no campo educativo etc. No que diz respeito à BNCC publicada em 2017, penso ser importante destacar que, na versão preliminar que o Ministério da Educação divulgou em 2015, havia a chamada para que fosse submetida a "amplo debate" pelas comunidades de professores e pesquisadores que, nas palavras do então Ministro da Educação, eram chamados a participar intensamente, pois, estaríamos "construindo o futuro do Brasil" (BRASIL, 2015, p. 2). Após um debate de especialistas no âmbito do Ministério, toda a sociedade foi conclamada a participar, visto que numa sociedade democrática a participação social ampla é o fundamento primeiro. Ora, sabemos todos das reviravoltas pelas quais passou a política brasileira entre 2015 e 2017; mas a produção biopolítica não para e neste ano foi publicada a versão definitiva da BNCC para o ensino fundamental. Ao longo do documento, a palavra cidadania aparece 19 vezes $^{10}$. Destacarei uma única passagem do texto em que a palavra aparece, tomando-a como indicativa do "tom político" do documento. Ao tratar dos anos finais do Ensino Fundamental, a BNCC afirma:

Em todas as etapas de escolarização, mas de modo especial entre os estudantes dessa fase do Ensino Fundamental, esses fatores frequentemente dificultam a convivência cotidiana e a aprendizagem, conduzindo ao desinteresse e à alienação e, não raro, à agressividade e ao fracasso escolar. Atenta a culturas distintas, não uniformes e nem contínuas dos estudantes dessa etapa, é necessário que a escola dialogue com a diversidade de formação e vivências para enfrentar com sucesso os desafios de seus propósitos educativos. A compreensão dos estudantes como sujeitos com histórias e saberes construídos nas interações com outras pessoas, tanto do entorno social mais próximo quanto do universo da cultura midiática e digital, fortalece o potencial da escola como espaço formador e orientador para a cidadania consciente, crítica e participativa. (BRASIL, 2017, p. 57-58).

Vê-se que a escola é afirmada como local de produção de cidadania, de preparação do estudante para um exercício crítico, consciente e participativo na

10 Talvez seja interessante notar que no documento preliminar de 2015 a palavra "cidadania" aparecia 49 vezes. Deixo as inferências políticas abertas ao leitor. 
sociedade, reafirmando os princípios definidos desde a Constituição de 1988 e a LDB de 1996. Não seria possível, no limite de um artigo, passar em revista toda a produção de políticas públicas em educação no Brasil nas últimas décadas; o que quis fazer aqui foi simplesmente delinear alguns de seus traços, de modo a desenhar os contornos daquilo que estou propondo denominar uma "governamentalidade democrática" no campo educativo. Está por ser feita uma análise do conjunto da produção de políticas públicas brasileiras, nos diversos campos, partindo da Constituição Federal de 1988, que coloca a cidadania como sua pedra de toque ${ }^{11}$. Um tal estudo, em extensão e em profundidade, traçaria de modo indelével nossa produção biopolítica e, penso, corroboraria a hipótese aqui esboçada.

Em suma, nas duas últimas décadas, uma intensa produção de políticas públicas pelo Ministério da Educação construiu todo um marco regulatório para o setor, centrada na afirmação e na promoção da cidadania, evidenciando uma governamentalidade democrática como maquinaria posta em curso no Brasil desde meados dos anos 1980, azeitada pela constituição de cidadãos. Traçado esse percurso da produção biopolítica (no campo da educação) na contemporaneidade brasileira, podemos voltar à problemática da subjetividade e lançar a questão: como somos subjetivados pela biopolítica operada pela governamentalidade democrática contemporânea no Brasil?

Somos assujeitados a cidadãos; somos, compulsoriamente, subjetivados para obedecer aos princípios básicos de uma sociedade democrática. Devemos participar; devemos confessar nossa verdade política no voto; devemos confessar nossa verdade técnica no trabalho; devemos confessar a verdade do que somos nos mais diversos processos sociais, porque somos cidadãos de direitos. Temos direito à educação, direito à saúde, direito ao trabalho etc., temos direito de ser, por isso somos. A biopolítica da governamentalidade democrática produz o "sujeito de direitos".

\section{Resistir?}

Se retomamos a dupla articulação assujeitamento/subjetivação, podemos inferir que, ao sermos subjetivados como cidadãos, no contexto da biopolítica da

11 Tenho procurado experimentar este viés analítico da governamentalidade democrática em alguns artigos, voltados para a compreensão do ensino de Filosofia (GALLO, 2012); da educação infantil (GALLO, 2015); e das políticas públicas de afirmação da diferença o campo educativo (GALLO, 2017) no Brasil contemporâneo. 
governamentalidade democrática brasileira contemporânea, somos assujeitados, mas isso também nos abre o panorama de atuarmos sobre nós mesmos. A questão é que a abrangência deste assujeitamento nos deixa cada vez menos brechas para interferirmos naquilo que somos; a maquinaria de poder nos enreda em teias cada vez mais complexas, de modo a praticamente não enxergar saídas. O ser sujeito na forma do cidadão configura, inclusive, como devemos agir sobre nós mesmos. Em outras palavras: mesmo naquilo que somos ativos, isso é produzido por um assujeitamento. Em outro lugar, argumentei que o trabalho de Foucault em torno do cuidado de si e dos processos de subjetivação que ele encontra na cultura de si da antiguidade grega e romana poderia ser visto como uma espécie de resistência à biopolítica e a seus múltiplos tentáculos ${ }^{12}$.

No texto publicado em 1982, e já citado aqui (O sujeito e o poder), Foucault (2014a, p. 123) destaca o duplo sentido da palavra "sujeito": estar submetido a outrem, por mecanismos de controle e jogos de poder, mas também estar em relação consigo mesmo por um "conhecimento de si", em ambos os casos, o sujeito é a marca de uma submissão. A partir desta constatação, o filósofo destaca três tipos de luta: aquelas que travamos contra os processos de dominação, como as lutas étnicas, sociais e religiosas; aquelas que travamos contra os processos de exploração, como as lutas dos trabalhadores contra a expropriação do produto de seu trabalho; e aquelas contra a submissão, isto é, contra os modos pelos quais somos subjetivados, somos constituídos como sujeitos. E afirma: "hoje, é a luta contra as formas de sujeição - contra a submissão da subjetividade - que prevalece cada vez mais, mesmo se as lutas contra a dominação e a exploração não desapareceram, muito pelo contrário" (FOUCAULT, 2014a, p. 123-124).

Ora, evidencia Foucault que a relação do sujeito com o poder implica em uma luta contra os processos de sujeição ou, em outras palavras, uma recusa daquilo que somos, uma vez que aquilo que somos é produzido pelo poder. Se esta é a principal das lutas que hoje travamos, este é, também, nosso principal problema filosófico e ético. Nas palavras de Foucault (2014a, p. 128):

Sem dúvida, o objetivo principal, hoje, não é descobrir, mas recusar o que nós somos. Devemos imaginar e construir o que poderíamos ser para nos livrarmos dessa espécie de "dupla obrigação" política que são a individualização e a totalização simultâneas das estruturas do poder moderno. Poder-se-ia dizer, para concluir, que o problema, ao mesmo tempo, político, ético, social e filosófico que se apresenta a nós, hoje, não é de tentar liberar o indivíduo do Estado e de suas instituições, mas de nos

12 Ver Gallo (2011). 
livrarmos, nós, do Estado e do tipo de individualização que a ele se prende. Precisamos promover novas formas de subjetividade, recusando o tipo de individualidade que se nos impôs durante vários séculos.

Fazendo funcionar esse programa de luta que nos oferece Foucault no contexto da produção biopolítica da governamentalidade democrática brasileira contemporânea, recusar o que somos é recusar essa cidadania de cunho neoliberal que nos tem sido imposta, não durante vários séculos, mas durante as últimas décadas, tempo suficiente para conformar um panorama subjetivo que nos constrange a agirmos social e politicamente segundo os princípios de uma participação representacional. Assim somos subjetivados nas escolas sob a égide de toda uma política pública que conforma as instituições educativas a tal produção subjetiva, mas também o somos nos vários serviços públicos, como a saúde e a previdência social, por exemplo, bem como pela mídia e por todo o entorno social. Como ser, se não somos cidadãos? Não é por acaso que a inclusão tem sido a lógica que preside a produção biopolítica brasileira ${ }^{13}$.

Se o primeiro passo para a construção de uma luta de resistência contra os processos de assujeitamento é o reconhecimento de como somos produzidos sujeitos, podemos encontrá-lo na governamentalidade democrática que nos subjetiva como cidadãos de direitos. O segundo passo é criarmos as ferramentas e as ações para resistir. Aqui nos ajuda novamente Foucault: não se trata de liberar o indivíduo do Estado e das instituições; é nela que somos constituídos, logo não podemos ser fora delas; mas, sendo constituídas nas e pelas instituições, podemos agir sobre nós mesmos, recusando aquilo que somos e investindo em transformações de nossos panoramas subjetivos.

Se a biopolítica é o governo da vida, a resistência pode ser a afirmação da vida para além de todo governo. Nessa direção, é muito potente o tratamento conceitual que encontramos em Aspis (2012) em torno da noção de re-existência. Resistir é re-existir, existir de novo, afirmar as potências da vida. Re-existir é recusar as subjetivações impostas e criar novas formas de subjetividade:

[...] considerando que não haja sociedade sem relações de poder, o agonismo entre poder e liberdade é uma tarefa incessante, uma tarefa política inerente à existência social, à existência de qualquer um na sociedade, o que vale dizer: a luta pela liberdade, a luta pelo desgoverno,

13 Temos já uma produção razoável analisando as políticas de inclusão pelo viés da biopolítica. Recomendo, por exemplo, Fabris; Klein, 2013. 
a resistência ao aprisionamento das possibilidades de ação pertence ao homem comum, é sua tarefa política. Insistir em existir, existir enquanto múltiplas possibilidades, existir enquanto sobreposição de sis (si e si e si e...), sempre renovados eus, palimpsestos, movimentos constantes de reinvenção, dervixes dançantes, devires, insistir em existir de novo e de novo: re-existir.

Re-existir: criação de novas formas de subjetividade. Recusar as formas de subjetivação que o Estado nos impõe. Recusar a ovelha e o rebanho, a "combinação tão astuciosa das técnicas de individuação e dos procedimentos de totalização" (FOUCAULT, 1995, p. 236) às quais o Estado-Pastor moderno quer nos sujeitar.

Escapar. Insistir em existir, imprevisíveis. (GALLO; ASPIS, 2011, p. 175-176).

Resistir à biopolítica é insistir na vida. Este é o campo que está aberto para nós. Recusar esse sujeito de direitos no qual fomos transformados para podermos ser democraticamente governados e insistir na vida para além de direitos e de governos, abrindo outros panoramas subjetivos. Os processos educativos, se nos conformam a esta subjetividade, podem também abrir outras formas de nos relacionarmos conosco, produzindo formas outras de vida ${ }^{14}$.

\section{REFERÊNCIAS}

ALTHUSSER, L. Sobre a reprodução. Petrópolis: Vozes, 1999.

ASPIS, R. P. L. Ensino de Filosofia e Resistência. Tese (doutorado em Educação) - Universidade Estadual de Campinas. Campinas, 2012.

AUDUREAU, J. P. Assujetissement et subjectivation: réflexions sur l'usage de Foucault en éducation. Révue Française de Pédagogie, n. 143, p. 17-29, avril-juin 2003.

BRASIL. Constituição da República Federativa do Brasil de 1988. 1988. Disponível em: <http://www.planalto.gov.br/ccivil_03/constituicao/constituicaocompilado.htm>. Acesso em: 30 jun. 2017.

14 Convém ressaltar aqui que o derradeiro trabalho de Foucault, A coragem da verdade (2011), no curso de 1984, implicou num estudo dos antigos filósofos cínicos como aqueles que investiram em uma vida outra, exercitada na praça pública. 
BRASIL. Lei $\mathrm{n}^{\circ}$. 9394, de 20 de dezembro de 1996. Estabelece Diretrizes e Bases da Educação Nacional. Diário Oficial da União, Brasília, DF, 23 dez. 1996. Disponível em: <http://www.planalto.gov.br/ccivil_03/leis/L9394.htm>. Acesso em: 30 jun. 2017.

BRASIL. Ministério da Educação. Base Nacional Comum Curricular - documento preliminar para debate público. Brasília: MEC, 2015.

BRASIL. Ministério da Educação. Base Nacional Comum Curricular - Ensino Fundamental. Brasília: MEC, 2017.

CASTRO, E. Vocabulário de Foucault. Belo Horizonte: Autêntica, 2009.

COMBES, M. La vie inséparée. Vie et sujet au temps de la biopolitique. Paris: Éditions Dittmar, 2011.

DELEUZE, G. Foucault. 2. ed. São Paulo: Brasiliense, 1991.

DREYFUS, H. L.; RABINOW, P. Michel Foucault beyond structuralism and hermeneutics. 2. ed. Chicago: The University of Chicago Press, 1983.

FABRIS, E. T. H.; KLEIN, R. R. (Org.). Inclusão e biopolítica. Belo Horizonte: Autêntica, 2013.

FOUCAULT, M. Vigiar e punir: história da violência nas prisões. 8. ed. Petrópolis: Vozes, 1991.

FOUCAULT, M. Em defesa da sociedade. São Paulo: Martins Fontes, 1999.

FOUCAULT, M. Verdade, poder e si mesmo. In: FOUCAULT, M. Ditos e Escritos - V. Rio de Janeiro: Forense Universitária, 2004. p. 294-300.

FOUCAULT, M. Segurança, território, população. São Paulo: Martins Fontes, 2008a.

FOUCAULT, M. Nascimento da biopolítica. São Paulo: Martins Fontes, 2008b.

FOUCAULT, M. A coragem da verdade. São Paulo: WMF Martins Fontes, 2011.

FOUCAULT, M. L'Origine de l'herméneutique de soi-conférences prononcés à Dartmouth College, 1980. Paris: Vrin, 2013.

FOUCAULT, M. O sujeito e o poder. In: FOUCAULT, M. Ditos e Escritos - IX. Rio de Janeiro: Forense Universitária, 2014a. p. 118-140.

FOUCAULT, M. As técnicas de si. In: FOUCAULT, M. Ditos e Escritos - IX. Rio de Janeiro: Forense Universitária, 2014b. p. 264-296.

FOUCAULT, M. Do governo dos vivos. São Paulo: WMF Martins Fontes, 2014c.

GALLO, S. Do cuidado de si como resistência à biopolítica. In: VEIGA NETO, A.; CASTELO BRANCO, G. (Org.). Foucault - Filosofia e Política. Belo Horizonte: Autêntica, 2011. p. 371-391.

GALLO, S. Governamentalidade democrática e ensino de filosofia no Brasil contemporâneo. Cadernos de Pesquisa, Fundação Carlos Chagas, v. 42, p. 48-64, 2012. 
GALLO, S. "O pequeno cidadão": sobre a condução da infância em uma governamentalidade democrática. In: RESENDE, H. (Org.). Michel Foucault: o governo da infância. Belo Horizonte: Autêntica, 2015. p. 329-343.

GALLO, S. Políticas da diferença e políticas públicas em educação no Brasil. Educação e Filosofia. Universidade Federal de Uberlândia, 2017. [no prelo].

GALLO; S.; ASPIS, R. L. Biopolítica-vírus e educação-governamentalidade e escapar e... Revista de Estudos Universitários, Sorocaba, v. 37, n. 2, p. 167-179, dez. 2011.

Texto recebido em 11 de julho de 2017. Texto aprovado em $1^{\circ}$ de agosto de 2017. 